methods of cord care which hasten the happy conclusion of this ritual seclusion. Policy makers should be aware that home cord care kits which prolong the time to cord separation may not be taken up by the target population.

M ELLIS GPO Box 5307, Prasuti Griha, Thapathali, Kathmandu, Nepal

1 Ronchera-Oms C, Hernandez C, Jimenez NV. Antiseptic cord care reduces bacterial colonization but delays cord detachment. Arch Dis Child 1994; 70: F70.

2 Woodruff AW, El Bashir E, Yugusuk A, Grant J, Baya El, El Suni A. Neonatal tetanus: mode Baya El, El Suni A. Neonatal tetanus. mode of infection, prevalence and preventid

\section{Cardiac arrest associated with} vancomycin in a neonate

EDITOR,-A 13 day old newborn girl was treated for an Escherichia coli infection with a once daily, 20 minute infusion of $150 \mathrm{mg}$ of ceftriaxone. Progress was normal until vancomycin $(150 \mathrm{mg})$ was mistakenly injected intravenously over 20 minutes. Within 10 minutes she stopped breathing and became cyanotic; pulse and cardiac sounds were absent. Bag ventilation with $100 \%$ oxygen and chest compressions were immediately started. An endotracheal intubation was performed. The infant recovered within one minute from her cardiac arrest. The evolution during the following 18 months has been favourable.

To our knowledge, four other cases of cardiac arrest after a rapid infusion of vancomycin have been reported involving one adult and three children. ${ }^{1-4}$ Of these, two infants died. No cardiac arrest in a newborn baby has been described before.

This report of a cardiac arrest in a neonate, after a rapid intravenous infection of vancomycin, strengthens the usual recommendation that this drug should be administered over a prolonged time. The proportion of young children (four out of five) among the reported cases might suggest that a rapid infusion of vancomycin could particularly lead to a cardiac arrest in this age group. This major side effect of vancomycin could be related to a neuromuscular blockage or a ventricular arrhythmia, ${ }^{2}$ a direct transient depression of the cardiac function, ${ }^{3}$ or an extreme form of an anaphylactoid reaction.

T BOUSSEMART J CARDONA M BERTHIER CHEVREL Paediatric Intensive Care Unit, University Hospital, BP 577 , 86021 Poitiers, France

1 Best CJ, Ewart M, Sumner E. Perioperative complications following the use of vancomycin in children: a report of two cases. Br $\mathcal{F}$ Anaesth 1989; 62: 576-7.

2 Glicklich D, Figura I. Vancomycin and cardiac arrest. Ann Intern Med 1984; 101: 880-1.

3 Mayhew JF, Deutsch S. Cardiac arrest following administration of vancomycin. Can Anaesth Soc f 1985; 32: 65-6.

4 Spears RL, Koch R. The use of vancomycin in pediatrics. Proceedings of the Seventh Annual Symposium on Antibiotics. 1959: 798-803.

\section{Intestinal dilatation in the fetus}

EDITOR,-Richards and Holmes have described a series of nine cases with intestinal dilatation in the fetus, all with surgical

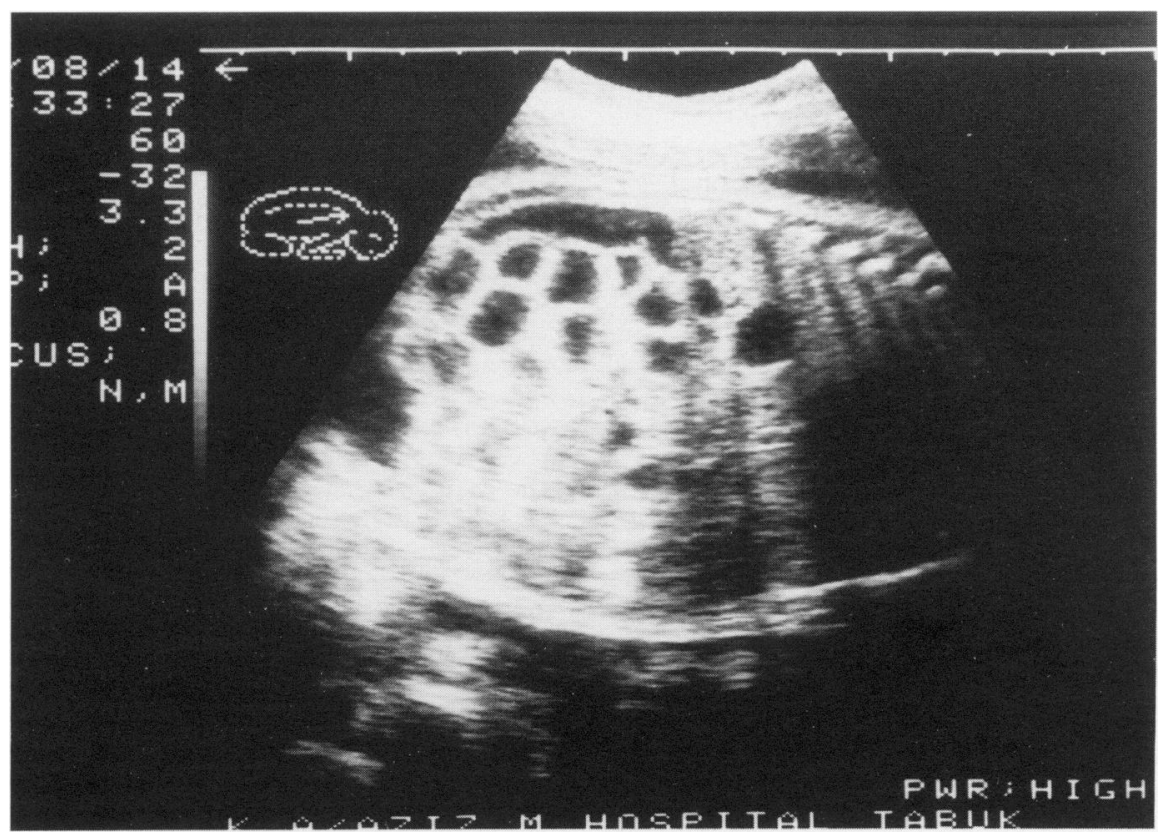

Antenatal ultrasound scan showing intestinal dilatation.

aetiology. ${ }^{1}$ Similar findings are also seen in congenital chloride diarrhoea. ${ }^{2}$

We admitted a baby girl after delivery, for observation and investigations for similar findings on antenatal ultrasound scan (figure). Physical examination was unremarkable as was a plain $x$-ray picture of the abdomen. Stools had the consistency of urine and could only be collected with a Foley's catheter in the rectum. Diagnosis of chloride diarrhoea was confirmed by a stool chloride of $137 \mathrm{mmol} / \mathrm{l}^{3}$ She responded satisfactorily to adequate fluid and electrolyte replacement.

It is quite easy to confuse the watery stools of congenital chloride diarrhoea with urine and thus miss the diagnosis. In an apparently normal child with a history of intestinal dilatation in the antenatal period, examination of the stools should be done before any invasive procedure such as suction biopsy.

A K GARG I AL HIFZI PO Box 100, Hospitals Program Tabuk, Saudi Arabia

1 Richards C, Holmes SJK. Intestinal dilatation in the fetus. Arch Dis Child 1995; 72: F135-9.

2 Patel PJ, Kolawale TM, BA'Aquell HS, Al-Jisu N Antenatal sonographic findings of congenital chloride diarrhoea. F Clin Ultrasound 1989; 17 3 Pearson AJG, Sladen GE, Edmonds CJ. The pathophysiology of congenital chloridiarrhoea. $Q \mathcal{F}$ Med 1973; 42: 453-66.

\section{Predictors for mortality}

EDITOR,-Kuint et al have presented the use of the change in the a:A ratio from just before dosing to one hour after dosing as a significant predictor of mortality. ${ }^{1}$ Their basis for recommending this predictor is its correlation with mortality. The traditional measures of the predictive ability of a model for dichotomous outcomes include rates of false positive and false negative results or equivalently, sensitivity and specificity. ${ }^{2} \mathrm{~A}$ model that has high predictive power will have low error rates or high specificity and sensitivity and thus correlation close to unity. However, the $\mathrm{P}$ value that Kuint et al report corresponds to a null hypothesis that the correlation is zero, whereas prognostic value depends on the correlation being close to unity. Ironically, they present false positive and negative rates from a model studied by Patterson et $a l,{ }^{3}$ and suggest that this model could be improved by the addition of a:A ratio, while failing to provide the same information for their own model. Without these rates, the prognostic value of a:A ratio for mortality cannot be evaluated.

BRIAN MITCHELL Pharmaceutical Biostatistics, Ross Products Division, Abbott Laboratories, 625 Cleveland Avenue, D105400-N2 Colombus OH 43215,
USA

1 Kuint J, Reichman B, Neumann L, Shinwell ES Prognostic value of the immediate response to surfactant. Arch Dis Child 1994; 71: F170-3.

2 Fleiss J. Statistical methods for rates and proportions. New York: Wiley, 1981: 4-8.

3 Patterson CC, Halliday HL. Prediction of outcome shortly after delivery for the very low birth weight $(<1500 \mathrm{~g})$ infant. Pediatr Perinat Epidemiol 1988: 2: 221-8

\section{Guidance after twin and singleton death}

EDITOR,-In relation to the perinatal death of a twin baby Dr de Kleine and colleagues recommend that all parents should be given a photograph of their babies together, as well as separately. ${ }^{1}$ Not all patents would feel comfortable about displaying a photograph of a stillborn baby, but an attractive picture of the two babies can readily be created (sometimes from two separate photographs). We would be happy to provide names of artists prepared to do this.

ELIZABETH BRYAN BARBARA READ The Multiple Births Foundation, Queen Charlotte's and Chelsea Hospital, Goldhawk Road, London W6 OXG

1 De Kleine M, Cuisinier M, Kollée L, Bethelham G, de Grauw K. Guidance after twin and singleton neonatal death. Arch Dis Child 1995; 36: F125-6. 